\title{
REVIEW
}

\section{Cannabis and glaucoma: A literature review}

\author{
Kathleen MacMillan, BSc(Pharm), ',2 Amanda Keddy, BSc(Pharm),' James Furlong, \\ BSc, BSc(Pharm)' \\ I. Class of 2019, Faculty of Pharmacy, Dalhousie University, Halifax, Nova Scotia, Canada \\ 2. Class of 2023, Faculty of Medicine, Dalhousie University, Halifax, Nova Scotia, Canada
}

\begin{abstract}
Introduction: Primary open-angle glaucoma (POAG) is characterized by the loss of retinal ganglion cells secondary to optic neuropathy; increased intraocular pressure (IOP) may or may not be present. Many treatment options focus on decreasing IOP measurements to attempt to prevent progression of glaucoma. Our literature review addressed a relatively common question; if cannabis is effective for treating elevated IOP in patients with glaucoma. Objective: To evaluate the current evidence for the use of cannabis for reducing IOP in glaucoma. Methods: PubMed, Embase, and the Cochrane Database were searched along with references drawn from full text articles published before January 2018 for the best available evidence that met the inclusion criteria. Three authors independently evaluated and selected the articles that represented the best available evidence. The selected articles were chosen based on study methodology and the type of cannabis used for the treatment of glaucoma. Randomized Control Trials were preferred, although lacking. No studies directly compared cannabis to the current standard of care medications for lowering IOP. Results: Five randomized controlled trials were included as best available evidence although they used different routes of administration. All studies included compared cannabis to placebo. The studies evaluated showed a range of IOP lowering effects and side effects. Topical administration has shown conflicting results for the treatment of glaucoma.Conclusion:The many forms of cannabinoid administration have demonstrated variable levels of effectiveness. The variability of the studies indicates the need for more research. Specifically, larger sample sizes, and comparison of standardized cannabis to current standards of care instead of placebo are strongly encouraged.
\end{abstract}

\section{Introduction}

Glaucoma is a serious medical condition projected to affect almost 80 million people by $2020^{1}$. There are two main types: open and closed-angle glaucoma. Primary open-angle glaucoma (POAG) is characterized by the loss of retinal ganglion cells secondary to optic neuropathy; an increased intraocular pressure (IOP) may or may not be present ${ }^{2,3}$. IOP has been demonstrated to fluctuate throughout the day, being highest in the morning ${ }^{4}$.

The goal of glaucoma therapy is to decrease IOP, as lower IOP has been shown in the Early Manifest Glaucoma Trial (EMGT) to slow the progression of glaucoma. In the EMGT, those treated to lower IOP levels had slower disease progression compared to control; specifically, for every $\mathrm{mm} \mathrm{Hg}$ decrease from baseline, there was approximately a $10 \%$ reduced risk of progression ${ }^{5,6}$.

While a variety of medication classes and individual agents are used in ophthalmic preparations to reduce IOP as part of glaucoma therapy, one commonly used combination is latanoprost and timolol eye drops ${ }^{7,8}$. This combination has been shown to decrease IOP in $73.5 \%$ of patients, by more than $30 \%$. 10 .

With the increasing popularity of natural health products, a possible alternative natural method for IOP lowering is the use of marijuana (Cannabis) ${ }^{11}$. Cannabis contains cannabinoids, which may be responsible for the therapeutic effects. Cannabidiol (CBD) and tetra- hydrocannabinol (THC) are thought to be the major contributors ${ }^{12}$. THC and CBD bind to endocannabinoid receptors. There are two types of endocannabinoid receptors found in humans: CB1 and CB2. Only CB1 receptors are known to be found in eye tissues. The evidence for CB2 receptors being located in the eye is less clear. Activating the CB1 receptor may be associated with an effect on IOP, indicating a possible mechanism of action for cannabis in the treatment of glaucoma $^{13,14}$.

The objective of this paper is to evaluate the current evidence for the use of cannabis for reducing IOP in glaucoma.

\section{Search Strategy}

PubMed, Embase, and the Cochrane Database were searched for studies published up to January 2018 using the terms "canna", "marijuana," "marihuana," "open," "angle," and "glaucoma" as keywords. No studies had progression of glaucoma as an outcome, so reduction in IOP was used as a surrogate. After removing duplicates, 77 unique articles were obtained, with one additional article being found through reviewing references, for a total of 78 articles. The authors independently evaluated these 78 articles and met in person to discuss their findings. They then came to consensus for five articles which were chosen as the best available evidence (Figure 1). 


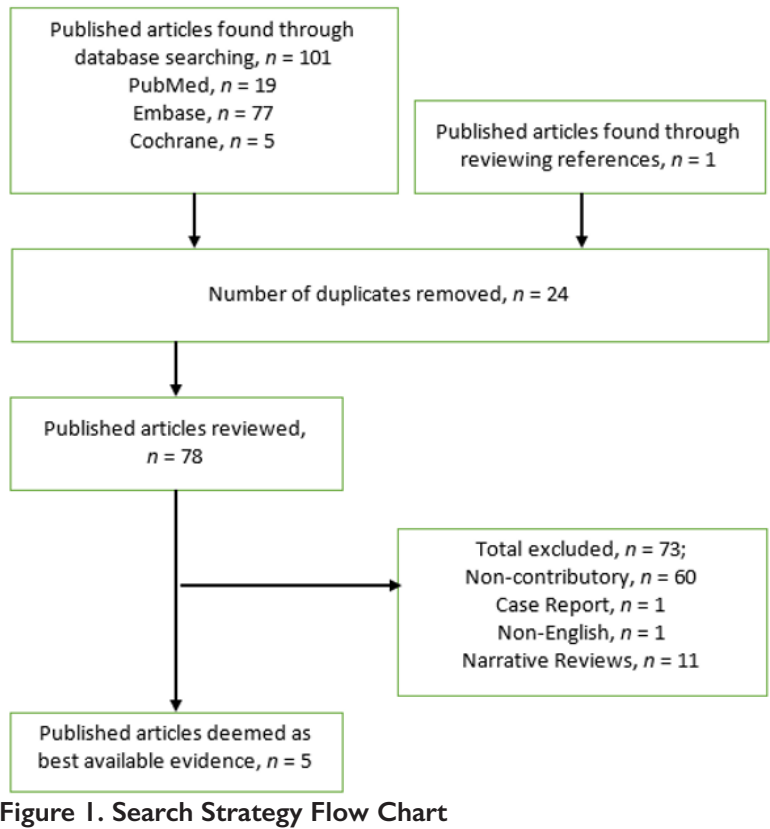

\section{Results}

The evidence regarding glaucoma and cannabis is limited by lack of research and small sample sizes. Studies were chosen that evaluated different forms of cannabis administration (e.g. smoked, oral, topical) with the best available evidence being selected for each dosage form based on the methodology (e.g. randomized, placebo-controlled) employed by the researchers. This report focuses on studies that evaluated the effect cannabinoids had on IOP in patients with glaucoma.

Five randomized controlled trials that tested cannabis as an IOP-lowering agent were selected as the best available evidence. One used smoked cannabis, two used topical drops, one used sublingual oromucosal spray, and one used oral capsules (Table 1) ${ }^{15-19}$. No articles compared cannabis directly to standard of care, only to placebo.

Merritt et al. conducted an experiment with 18 adults (6 with secondary glaucoma, 12 with POAG including seven with juvenile open angle glaucoma) who stopped their prescribed glaucoma treatment 48 hours before smoking either cannabis or placebo cigarettes. The study did not specify which glaucoma medications were stopped at the beginning of the washout period. The placebo cigarettes had the same smell and taste as the cannabis cigarettes as they were cannabis cigarettes which had the alcohol extractable cannabinoids removed with only a sugar and cellulose residue remaining to maintain binding. Each cannabis cigarette was $2 \%$ delta 9 -THC by weight. The authors did not report the percentage of CBD in the cannabis cigarettes.
The average IOP decrease at 90 minutes was 6.6 $\pm 1.5 \mathrm{~mm} \mathrm{Hg}$ in the treatment group with no difference in the placebo group in the same time frame ( $p$ $<0.05)^{15}$. The reduction lasted for approximately three hours, but there were various side effects (e.g. altered perception) with the worst being severe hypotension (Table 1). One patient had their blood pressure drop precipitously to the point where their IOP was $1-2 \mathrm{~mm}$ $\mathrm{Hg}$ in their right eye. A second patient had a similar blood pressure response with their IOP dropping to 3 $\mathrm{mm} \mathrm{Hg}$ in their left eye and $14 \mathrm{~mm} \mathrm{Hg}$ in their right eye (normal IOP range $12-22 \mathrm{~mm} \mathrm{Hg}$ ). Both patients had their blood pressure spontaneously restored via a reclining position. 15

This trial was limited by a small sample size, but found statistical significance in IOP reduction using smoked cannabis, indicating sufficient power for this outcome. The authors did not describe the randomization method. Although this study was blinded, the strength of blinding is not clear as we have no way to confirm if the placebo cigarettes and cannabis cigarettes truly did have the same smell and taste, which serves as a further limitation. In addition, the authors did not state the CBD concentration in either cigarette so it is unknown how CBD affects the outcome. A final limitation is that there was no repeat administration; only one cigarette, cannabis or placebo, was smoked by each adult. Due to the lack of repeat administration, we have no data on the long-term efficacy and safety of smoking cannabis for IOP reduction. ${ }^{15}$

Merritt et al. conducted a further study with applied ocular cannabis to determine if a different delivery system would be as efficacious as cannabis cigarettes while having fewer systemic side effects. Six participants with primary open angle glaucoma were included in the study. The participants discontinued their glaucoma medications 36 hours prior to using the eye drops in the study. The eye drops administered were $0 \%$ (placebo), $0.05 \%$, or $0.1 \%$ THC in light mineral oil. The treatment was randomly assigned and, after administration, the IOP of each eye was obtained hourly for 10 hours. This procedure was repeated until each participant had used all three drops, with at least 24 hours between treatments. ${ }^{16}$

The authors found that there was no significant difference between the three treatments as the mean \pm standard deviation for the treatment groups' IOP measurements overlapped at all measurement times. Also, the same eye was used for different treatments, but there was no note of contralateral effects. ${ }^{20}$ In addition, it is unknown how mineral oil affects the penetration of the active ingredient into the tissues of the eye. A further limitation of this study is that each treatment was only 24 hours, which may have been an inadequate timeframe for the medication to have a 
Table I: Post-simulation survey results from preclerkship trainees. $\mathbf{R}=$ randomized; $\mathrm{PC}=$ placebo controlled; $\mathrm{DB}=$ double masked; NSS = not statistically significant; $\mathrm{Hx}=$ history; $\mathrm{Tx}=$ treatment

\begin{tabular}{|c|c|c|c|c|c|c|}
\hline Study & Design & $N$ & Participiants & Intervention & Results & Side effects \\
\hline $\begin{array}{l}\text { Merritt } \\
\text { et al., } \\
1980\end{array}$ & $\mathrm{R}, \mathrm{PC}$ & 18 & $\begin{array}{l}\text { Adults: } 28-7 \text { I (mean } \\
45 \text { years); } \\
6 \text { female, } 12 \text { male }\end{array}$ & $\begin{array}{l}\text { One Marijuana cigarette }(2 \% \\
\text { d-9-THC) }\end{array}$ & $\begin{array}{l}\text { IOP peak decrease } 6.6+ \\
\text { I.5 mm Hg at } 90 \text { mins. } \\
\text { Placebo NSS }(p<0.05)\end{array}$ & $\begin{array}{l}\text { Altered perception ( } 18 / / 8) \text {; } \\
\text { tachycardia and palpitations } \\
\text { with anxiety }(8 / 18) ; \text { Postural } \\
\text { hypotension }(5 / 18) ; \text { bulbar } \\
\text { conjunctival hyperemia and } \\
\text { ptosis }(9 / / 8)\end{array}$ \\
\hline $\begin{array}{l}\text { Merritt } \\
\text { et al., } \\
1981\end{array}$ & $\begin{array}{l}\text { R, PC, } \\
\text { balanced } \\
\text { protocol } \\
\text { of Lat- } \\
\text { in-square } \\
\text { design }\end{array}$ & 6 & $\begin{array}{l}\text { Adults: } 52-73 \text { (mean } \\
57 \text { years); } \\
4 \text { female; } 2 \text { males }\end{array}$ & $\begin{array}{l}\text { Placebo: light mineral oil } \\
\text { eye drop } \\
\text { Experimental Drop I: } \\
0.05 \% \mathrm{THC} \text { in light mineral } \\
\text { oil } \\
\text { Experimental Drop 2: } \\
0.1 \% \mathrm{THC} \text { in light mineral } \\
\text { oil vehicle }\end{array}$ & $\begin{array}{l}\text { NSS between } 0.05 \%, 0.1 \% \\
\text { or placebo }\end{array}$ & Not explicitly stated \\
\hline $\begin{array}{l}\text { Porcella } \\
\text { et al., } \\
2001\end{array}$ & $\mathrm{R}, \mathrm{PC}$ & 8 & $\begin{array}{l}\text { Adults: } 2 \text { I-72 (mean } \\
48) ; 3 \text { female, } 5 \\
\text { male with IOP > } \\
22 \mathrm{mmHg} \text { bilateral } \\
\text { glaucoma }\end{array}$ & $\begin{array}{l}\text { Topical administration of } \\
\text { two drops } 25 \text { or } 50 \text { mcg } \\
\text { WIN-55-2 I } 2-2 \text { or vehicle } \\
\text { solution (I } 50 \text { millimolar } \\
\mathrm{NaCl} \text { and } 45 \% 2 \text {-hydroxyl- } \\
\text { propyl- } \beta \text {-cyclodextrin) }\end{array}$ & $\begin{array}{l}\text { Initial IOP measurements } \\
\text { at baseline ranged from } \\
22-31 \mathrm{mmHg} \\
\text { IOP at } 30 \text { minutes: } \\
25 \mathrm{mcg} T \mathrm{Tx}-15+0.6 \% \\
50 \mathrm{mcg} \mathrm{Tx}:-23+0.9 \% \\
\\
\text { IOP after } 60 \text { minutes: } \\
25 \text { mcg Tx: }-20+0.7 \% \\
50 \text { mcg Tx: }-31+0.6 \% \\
\text { Maximum effect seen at } \\
60 \text { minutes. }\end{array}$ & Not explicitly stated \\
\hline $\begin{array}{l}\text { Tomida } \\
\text { et al., } \\
2006\end{array}$ & $\begin{array}{l}\text { R, PC, } \\
\text { DB }\end{array}$ & 6 & $\begin{array}{l}\text { Males with ocular } \\
\text { hypertension or } \\
\text { POAG (mean age } \\
55.3 \text { ). IOP of }>24 \\
\mathrm{mmHg} \text { and }<36 \\
\mathrm{mmHg} \text { in at least } \\
\text { one eye, and } \mathrm{MD} \\
<6 \mathrm{~dB}\end{array}$ & $\begin{array}{l}\text { Sublingual administration us- } \\
\text { ing a randomized schedule: } \\
\text { Placebo } \\
5 \mathrm{mg} \text { of delta-9-THC } \\
20 \mathrm{mg} \text { of CBD } \\
40 \mathrm{mg} \text { of CBD }\end{array}$ & $\begin{array}{l}\text { Mean mmHg Before } \\
\text { treatment: } \\
5 \text { mg THC Tx: } 27.38 \\
40 \text { mg CBD Tx: } 27.58 \\
\text { Placebo Tx: } 27.38 \\
\text { Mean mmHg Two hours } \\
\text { post treatment: } \\
\text { 5mg THC Tx: } 23.5 \\
\text { Placebo: } 27.37 \\
\text { P=0.026 } \\
\text { Mean IOP (mmHg) Four } \\
\text { hours post treatment: } \\
40 \text { mg CBD Tx: } 25.92 \\
\text { Placebo Tx: } 23.21 \\
\text { P=0.028 } \\
\text { CBD did not reduce the } \\
\text { IOP as much as placebo. }\end{array}$ & $\begin{array}{l}\text { THC (5 mg): } \\
\text { Oral pain/discomfort (I/6); } \\
\text { Dizziness (I/6); Hypotension } \\
\text { (I/6); Nausea (I/6); Panic } \\
\text { (I/6); Photopsia (I/6) } \\
\\
\text { CBD (20 mg): Diastolic } \\
\text { pressure increase (2/6); } \\
\text { Dizziness (I/6); Disturbed } \\
\text { attention (I/6) } \\
\text { CBD (40 mg): Oral pain/ } \\
\text { discomfort (3/6); wPharyn- } \\
\text { gitis (2/6); Bad taste (I/6); } \\
\text { Feeling hot (I/6);Throat } \\
\text { irritation (I/6) }\end{array}$ \\
\hline
\end{tabular}

possible effect on IOP, if one were to occur. In addition, two-thirds of the patients had prior eye surgery for their POAG, suggesting the results are not generalizable to the average patient with POAG. ${ }^{16}$

Porcella et al. also used topical therapy on eight participants, of which only one was documented as open angle, the remaining seven had other forms of glaucoma that were resistant to traditional therapy at the time of publication. Participants received topical
WIN55-212-2, a synthetic CB1 agonist, at either 25 or 50 mcg doses, after a 12-hour washout period. IOP measurements had a maximum decrease of $20 \pm$ $0.7 \%$ for the $25 \mathrm{mcg}$ dose $(\mathrm{P}<0.05)$ and $31 \pm 0.6 \%$ for the $50 \mathrm{mcg}$ dose $(\mathrm{P}<0.01)$ an hour after administration compared to baseline. In this study, each participant acted as their own control, as only one eye was treated. The authors mention an effect on the contralateral untreated eye, which was found to not be statistically 
significant. IOP was measured twice and averaged 30 minutes before treatment, and every fifteen minutes for three hours after administration with no direct placebo comparison. Measurement of IOP was performed by an observer unaware of which eye was being treated. However, the sample size of the study was small, and the untreated eye also showed a decrease in IOP at one hour post-dose. ${ }^{17}$

Another study focused on patients with POAG by Tomida et al. included three participants who were actively using glaucoma treatment and three who were not on IOP-lowering medication. Prior to starting the study, patients who were taking IOP lowering medications underwent a four to six-week washout period. The study required participants to complete weekly visits for six weeks. During the first weekly visit, the patients had baseline IOP measurements collected and no treatment was administered. During the following four weeks, all six participants were given one dose of an extract containing THC (5 mg), CBD (20 $\mathrm{mg}$ or $40 \mathrm{mg}$ ) or placebo which were randomly assigned and administered using an oromucosal spray. Over four weeks, each patient received all four treatment options. However, the authors did not discuss other compounds which may have been included in the extract as they used the whole plant. IOP was measured before receiving the medication, and again one, two, three, four, six, and twelve hours post-treatment. Two to three IOP measurements were recorded at each time interval and averaged. The collected data were analyzed using t-tests for paired samples to compare the treatment groups to placebo. This analysis found that THC decreased IOP significantly (14\% decrease) compared to placebo (0.04\% decrease) $(\mathrm{p}=0.026)$, and CBD dosed at $40 \mathrm{mg}$ was shown to also significantly decrease IOP four hours after treatment (6\% decrease) compared to placebo (15\% decrease) $(\mathrm{p}=0.028)$, although these findings were not clinically relevant as noted by the authors (Table 1). The study is lacking in regards to how the sample size was determined (only six participants) and it does not describe the purpose of the final weekly visit. Statistical data was incomplete as confidence intervals were not described and their double-masking method was not explained. ${ }^{18}$

Tiedeman et al. conducted a study on 44 ocular hypertensive patients to test two oral delta 1-THC compounds with unique side chain modifications. A total of 16 and 28 participants were included in the two study branches (BW29Y and BW146Y). The $8 \mathrm{mg}$ and 12 mg doses in the two BW146Y arms of the study showed a mean IOP reduction of 6 and $9 \mathrm{~mm} \mathrm{Hg}$, respectively, at four hours, which were statistically significant (Table 1). Regarding the BW29Y treatment, no statistically significant change was found in IOP when compared to placebo (Table 1). The study's limitations include a small sample size and not adequately describing their methods of randomization and blinding ${ }^{19}$. Also, participants were only given the treatment once, their IOP was measured the same day they received treatment, and they were followed up at one week and four weeks. The rationale for follow-up following a single dose over one month was not fully explained, although it appeared to be monitoring for adverse effects. It is unknown whether or not IOP lowering medications were stopped prior to the participants receiving study treatment.

The studies included in our review had several flaws. The washout period for previous glaucoma medications varied significantly between studies, ranging from 12 hours to six weeks, with one study not providing details. ${ }^{17-19}$ Several studies included patients who had mixed types of glaucoma, not just POAG. ${ }^{15,17-19}$ These limitations make it difficult to generalize these results to the average patient with glaucoma. Furthermore, it was not always specified which glaucoma medications all of the participants were using prior to taking part in the studies. ${ }^{15,16,19}$ One major flaw of all the trials was that the timing of IOP measurement was not specified. IOP fluctuates throughout the day, and not having a standardized time may influence the measurement. ${ }^{4}$ There are many limitations in all the trials, specifically the use of different dosage forms and different ratios of THC and CBD being used. As mentioned previously, these trials do not provide any long-term safety and efficacy data. ${ }^{15-19}$

Many side effects were described throughout the trials, including altered sensation, dizziness, nausea, hunger, and drowsiness. Tachycardia with anxiety and severe hypotension were the most severe side effects reported. ${ }^{5,16,18,19}$

It should also be noted that both the Canadian Ophthalmological Society of Canada and the American Academy of Ophthalmology do not recommend the use of cannabis as a treatment for glaucoma at this time. The lack of evidence as a long-term treatment strategy, short duration of action, risk of undesired side effects, and no great evidence on long-term safety of the drug prevent the recommendation for the use of cannabis as a treatment for elevated IOP in glaucoma. ${ }^{21,22}$

\section{Conclusion}

Studies have indicated cannabis may have the potential to lower IOP, however the quality of available literature is poor. The studies that were reviewed were highly variable in their methods and patient population selected, and therefore no current evidence supports the use of any form of cannabis to replace existing 
therapy for glaucoma. Until further research in the form of RCTs with more evidence to support the use of cannabis for lowering IOP, it should not be recommended at this time. When it comes to reduction of IOP, all dosage forms used had a short duration of action and it is unknown how many hours this effect may last, or even if it will prevent glaucoma progression long-term. If patients were to use this therapy, they would require frequent dosing, which has the potential to reduce patient adherence and increase side effects of the medication.

\section{Acknowledgements}

Susan Mansour, Director and Associate Professor and Assistant Dean, Faculty of Health, Dalhousie University provided review and feedback.

\section{References}

1. Quigley HA, Broman AT. The number of people with glaucoma worldwide in 2010 and 2020. Br J Ophthalmol 2006;90(3):262267.

2. Weinreb RN, Aung T, Medeiros FA. The pathophysiology and treatment of glaucoma: a review. JAMA 2014 May 14;311(18):1901-1911.

3. Canadian Ophthalmological Society. Canadian ophthalmological society evidence-based clinical practice guidelines for the management of glaucoma in the adult eye. CJO 2009;44(1):01/20/2018-1-100.

4. Clemens SL, et al. Fluctuations of intraocular pressure during the day in open-angle glaucoma, normal-tension glaucoma and normal subjects. J Appl Theory 199811 April;212(2):115-9.

5. Heijl A, Leske MC, Hyman L, Bengtsson B, Hussein M. Reduction of intraocular pressure and glaucoma progression: results from the Early Manifest Glaucoma Trial. Arch Ophthalmol 2002;120(10):1268-1279.

6. Leske $\mathrm{MC}$, et al. Factors for glaucoma progression and the effect of treatment: the early manifest glaucoma trial. Arch Ophthalmol 2003;121(1):48-56.

7. Li T, et al. Comparative effectiveness of first-line medications for primary open angle glaucoma-a systematic review and network meta-analysis. Ophthalmology 2016;123(1):129-140.

8. Konstas AG, et al. 24-hour efficacy of travoprost/timolol BAK-free versus latanoprost/timolol fixed combination in patients insufficiently controlled with latanoprost. Adv Ther 2014;31(6):592-603.
9. Higginbotham E, et al. Fixed combination of latanoprost and timolol vs individual components for primary open-angle glaucoma or ocular hypertension: a randomized, double-masked study. Arch Ophthalmol 2010;128(2):165-172.

10. Higginbotham E, Feldman R, Stiles M, Dubiner H. Latanoprost and timolol combination therapy vs monotherapy: one-year randomized trial. Arch Ophthalmol 2002;120(7):915-922.

11. Beidoe G, Mousa S. Current primary open-angle glaucoma treatments and future directions. Clin Ophthalmol 2012;6:16991707.

12. Atakan Z. Cannabis, a complex plant: different compounds and different effects on individuals. Therapeutic Advances in Psychopharmacology 2012 12;2(6):241-254.

13. Pertwee RG. The diverse CB1 and CB2 receptor pharmacology of three plant cannabinoids: $\Delta 9$-tetrahydrocannabinol, cannabidiol and $\Delta 9$-tetrahydrocannabivarin. Br J Pharmacol 2007 08/07;153(2):199-215.

14. Chen J, et al. Finding of endocannabinoids in human eye tissues: implications for glaucoma. Biochem Biophys Res Commun 2005 May 20;330(4):1062-1067.

15. Merritt J.C, Crawford W.J, Alexander P.C. Effect of marihuana on intraocular and blood pressure in glaucoma. Ophthalmology 1980;87(3):222-228.

16. Merritt J.C, Perry D.D, Russell D.N, Jones B.F. Topical delta 9-tetrahydrocannabinol and aqueous dynamics in glaucoma. J Clin Pharmacol 1981;21(8-9):467S-471S.

17. Porcella A, Maxia C, Gessa GL, Pani L. The synthetic cannabinoid WIN55212-2 decreases the intraocular pressure in human glaucoma resistant to conventional therapies. Eur J Neurosci 2001 Jan;13(2):409-412.

18. Tomida I, et al. Effect of sublingual application of cannabinoids on intraocular pressure: A pilot study; GW(United Kingdom). J Glaucoma 2006;15(5):349-353.

19. Tiedeman J.S, Shields M.B, Weber P.A. Effect of synthetic cannabinoids on elevated intraocular pressure. Ophthalmology 1981;88(3):270-277.

20. Piltz J, et al. Contralateral effect of topical beta-adrenergic antagonists in initial one-eyed trials in the ocular hypertension treatment study. Am J Ophthalmol 2000:130(4):441-453.

21. Rafuse P, Buys Y. Medical use of cannabis for glaucoma [Internet]. Canadian Ophthalmological Society; 2018 [cited 2019 Oct 22]. Available from: https://www.cos-sco.ca/ wp-content/uploads/2018/10/MedUseCannabisGlaucoma-COS_CGS.pdf

22. American Academy of Ophthalmology Reiterates Position that Marijuana is Not Proven Treatment for Glaucoma [Internet]. American Academy of Ophthalmology. American Academy of Ophthalmology; 2014 [cited 2019 Oct 22]. Available from: https://www.aao.org/newsroom/news-releases/detail/american-academy-of-ophthalmology-reiterates-posit 